\title{
La interrelación monumento-paisaje centra las XII Jornadas de Restauración del Patrimonio
}

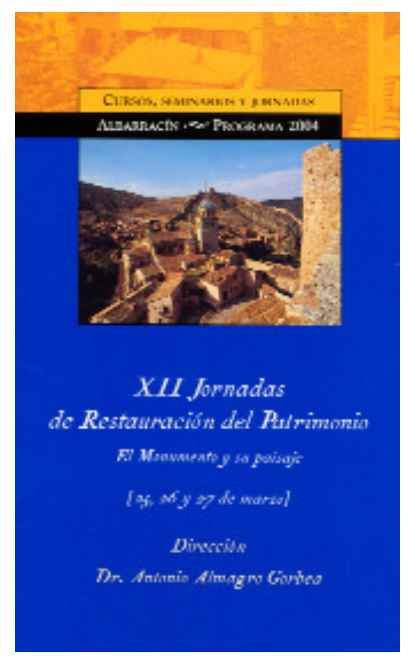

Folleto de las XII Jornadas y vista de Albarracin, sede del encuentro
Del 25 al 27 de marzo de 2004 se celebraron en Albarracin (Teruel) las XII Jornadas de Restauración del Patrimonio, organizadas por la Fundación Santa María de Albarracín, bajo el tema de El Monumento y su Paisaje.

La reflexión de partida que ha conducido a escoger el tema de este año parte de considerar que la conservación de los valores del Patrimonio difícilmente puede entenderse sin que alcance a todo su contexto, tanto físico como inmaterial. En el Patrimonio Arquitectónico el marco físico puede ser un medio urbano, un medio natural o también de carácter mixto. En todos los casos existe siempre una interrelación, pues el entorno condiciona generalmente la existencia y la forma del bien patrimonial y éste a su vez influye en la conformación de aquél.

El entorno puede entenderse y analizarse como paisaje y muchas veces sus valores son consustanciales a los del edificio, monumento o conjunto urbano, hasta el punto de que difícilmente se comprende el uno sin el otro. Cada vez con mayor frecuencia consideramos el territorio como parte del monumento que en él se asienta y tenemos que buscar su protección y conservación como forma de conservar la integridad del mismo. Los valores del entorno llegan en ciertos casos a tener tal relevancia que son incluso superiores a los de la propia obra arquitectónica. La preservación de estos valores del paisaje ligado a monumentos o conjuntos urbanos requiere de técnicas de análisis específicas y de métodos de intervención que han sido el objeto de estudio en estas jornadas.

Los distintos temas abordados en las jornadas han ido desde consideraciones generales sobre el paisaje, tanto urbano como natural, a los de carácter jurídico y al análisis de casos concretos. Entre las comunicaciones de carácter general cabe destacar las reflexiones en torno a la forma de ver y considerar los entornos urbanos y de monumentos aislados por parte de la propia sociedad que los vive o de los profesionales con una especial sensibilidad hacia el tema. En el primer caso, se analizó de un modo particular el caso de la ciudad de Valencia y la visión que de la misma se ha tenido a lo largo de la historia. En los aspectos jurídicos se ha puesto de manifiesto el carácter, en cierto modo pionero, que en esta cuestión ha tenido la legislación española, pese a que su aplicación, como en tantas ocasiones, no haya tenido una efectividad adecuada.

En todo caso se ha podido comprobar, tanto desde la perspectiva jurídica como desde el análisis de casos prácticos, la dificultad que entraña establecer normativas eficaces para la protección de los entornos desde un punto de vista cada vez más genérico en el que se aborden no sólo aspectos físicos, sino también otros de carácter inmaterial. La consideración del Patrimonio desde afecciones cada día más amplias complica de manera creciente el modo de abordar su preservación tanto por el mayor alcance físico de la protección (áreas más extensas con vinculación) con un creciente número de afectados, como por su mayor complejidad al abordar aspectos muy diversos, lo que obliga para su adecuada definición a realizar estudios multidisciplinares en ámbitos cada vez más dispares.

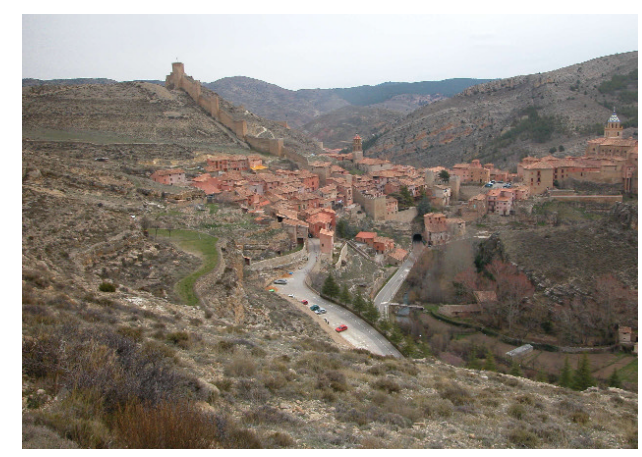

En la presentación de algunos temas concretos se han podido constatar las dificultades antes aludidas y la todavía escasa experiencia con la que contamos. El entorno de la catedral de Vitoria, con un debate actualmente abierto alrededor de la evolución de los distintas criterios y soluciones propuestos en estos últimos años, el problema de los restos arquitectónicos arruinados y el valor de sus entornos, o la importancia de los paisajes vinculados a monumentos singulares como es el caso del Palacio de Valsaín o el Monasterio del Paular, han ilustrado dentro de las jornadas la distinta problemática que se plantea. También, como muestra de un modo de intervenir, se presentaron algunos ejemplos de actuación en entornos urbanos, para minimizar el impacto de determinadas tipologías hoy muy en uso (casas unifamiliares adosadas) por medio de pequeñas modificaciones en su diseño y de un empleo inteligente de la vegetación.

Más información:

Fundación Santa María de Albarracín

Tel.: 978710093

Correo-e.: fsmalbarracin@aragob.es

Web: www.fundacionsantamariadealbarracin.com

Antonio Almagro

Director de las Jornadas

Arquitecto, director de la Escuela de Estudios

Árabes de Granada e investigador del CSIC 